Gut, 1986, 27, 1312-1319

\title{
Serum cholesterol precursor sterols in coeliac disease: Effects of gluten free diet and cholestyramine
}

\author{
MATTI VUORISTO AND TATU A MIETTINEN \\ From the Second Department of Medicine, University of Helsinki, Helsinki, Finland
}

SUMMARY Enhanced biliary secretion and high faecal excretion of cholesterol are associated with increased cholesterol synthesis in coeliac disease. We have further investigated cholesterol synthesis in coeliac disease by determining the concentrations of faecal steroids and cholesterol precursors in serum, with and without a gluten free diet and while taking cholestyramine. The levels of unesterified methyl sterols and free and esterified lathosterol, but not those of squalene and desmosterol, were increased in proportion to the level of cholesterol synthesis, as measured with the sterol balance technique. Serum esterified methyl sterol concentrations were also slightly higher but, unlike free methyl sterols or lathosterol, they were not significantly correlated with cholesterol synthesis. The gluten free diet decreased the level of cholesterol synthesis, and the levels of lathosterol and free methyl sterols. There was less decrease in the concentration of esterified methyl sterols, and an insignificant decrease in the concentrations of squalene and desmosterol. Cholestyramine lowered the serum cholesterol concentration and increased that of serum free methyl sterols less in the patients than in the controls, and the increase was proportionate to increase of cholesterol elimination (or synthesis). The increase of serum free methyl sterols per unit of the increase of cholesterol elimination (or synthesis) was three times higher in the bile acid malabsorption caused by cholestyramine than in the cholesterol malabsorption caused by gluten enteropathy. On the other hand, the decrease in the level of serum cholesterol relative to the increase in cholesterol elimination (or synthesis) was higher in cholesterol malabsorption due to coeliac disease than in cholestyramine induced bile acid malabsorption. Effective secretion of newly synthesised and/or absorbed cholesterol directly into the bile could be a factor in the marked decrease of the serum cholesterol concentration in coeliac disease.

In coeliac disease the elimination of cholesterol in the form of faecal neutral steroids is markedly increased, whereas faecal bile acid excretion is usually unchanged. ${ }^{1}$ Subsequent studies revealed that the mucosal cholesterol loss was not significantly increased, while biliary cholesterol secretion was almost doubled ${ }^{2}$ so that, despite low fractional absorption of cholesterol, its absorption in absolute terms was within the control limits. ${ }^{3}$ Consequently, the high sterol loss in coeliac disease appears to be mainly of biliary origin, and in the long term this loss must be balanced by increased cholesterol synthesis. ${ }^{1}$ The site of this increase, however, is at the moment unknown. Although intestinal cholesterolgenesis in vitro is greatly enhanced in

Address for correspondence: Prof Tatu A Miettinen, MD, Second Department of Medicine, University of Helsinki, SF-00290 Helsinki, Finland Received for publication 7 February 1986. coeliac disease,${ }^{45}$ its role in vivo is unclear. Also, there is no information on hepatic cholesterol synthesis in coeliac disease.

In the present study we explored cholesterol metabolism in coeliac disease further using two separate procedures to detect changes in cholesterol synthesis. These are the sterol balance technique and the quantification of cholesterol precursors in serum before and after gluten free diet, and before and after cholestyramine induced bile acid malabsorption. According to previous studies serum cholesterol precursors (Fig. 1), especially free methyl sterols and lathosterol, are closely parallel with the changes of cholesterol synthesis, most likely in the liver. ${ }^{6-10}$ Thus the main aims of the present experiments were first to explore the significance of the cholesterol precursors for the detection of increased cholesterol synthesis in cholesterol malab- 


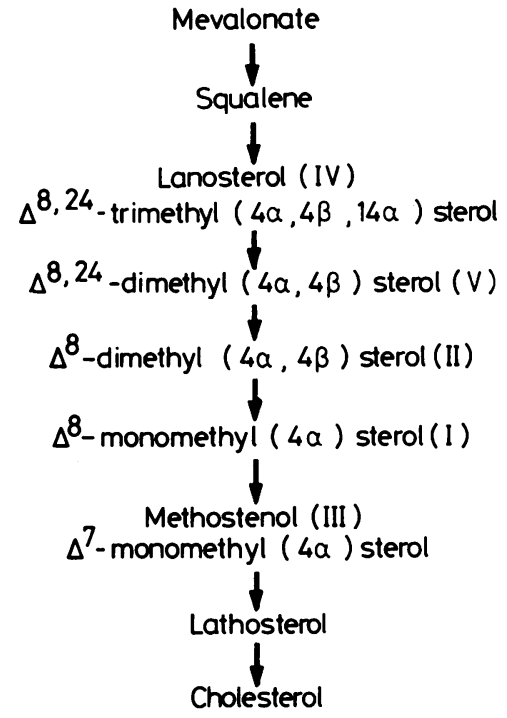

Fig. 1 Scheme for the metabolism of the main methyl sterols in cholesterol synthesis. Order of gas liquid chromatographic peaks in parentheses.

sorption of coeliac disease; and, second, to explore the differences in the effects of cholesterol and bile acid malabsorption on cholesterol metabolism.

\section{Methods}

\section{PATIENTS}

The present series comprised 12 patients with established coeliac disease. The correction of jejunal mucosal damage during a gluten free diet was regarded as an essential criterion for the diagnosis of coeliac disease. The control group consisted of six healthy subjects. All the subjects were informed of the purpose and design of the investigations, and they participated in the study as volunteers. The design of the study was approved by the ethical committee of the hospital. The faecal steroid data have, in part, been presented previously in Gastroenterology. ${ }^{1}$

Every patient was hospitalised and put on a low cholesterol $(125 \mathrm{mg} / 2400 \mathrm{kcal})$ solid food diet, which contained $100 \mathrm{~g}$ fat per day. The daily energy content of $30-35 \mathrm{kcal} / \mathrm{kg}$ of body weight was adjusted to maintain a constant body weight during the study. The controls were studied under similar conditions. All the subjects received $600 \mathrm{mg} /$ day of both beta-sitosterol and chromic oxide $\left(\mathrm{Cr}_{2} \mathrm{O}_{3}\right)$ (both from Otion Ltd., Helsinki, Finland) to correct, respectively, for a possible degradation of the sterol nucleus during intestinal transit, ${ }^{11}$ and for faecal flow. ${ }^{12}$ Both substances were given in capsules of $200 \mathrm{mg}$ three times a day. When the diet and the markers had been used for seven days, a three day stool collection was made to study faecal steroid excretions and faecal fat content.

Five of the patients and the six control subjects also volunteered for the cholestyramine trial. For this the subjects received cholestyramine $32 \mathrm{~g} /$ day, in four doses daily for up to 14 days, a three day stool collection being made at the end of the treatment period.

\section{CHEMICAL ANALYSIS}

Levels of serum squalene, free and esterified methyl sterols, and cholesterol were determined using thin-layer chromatography and gas liquid chromatography. ${ }^{6}$ Using mass spectrometric analysis, ${ }^{13}$ it was found that fraction I contained $\triangle^{8}$-methostenol and some dihydrolanosterol, fraction II monounsaturated dimethyl sterol $(4,4 \alpha-$ dimethyl $\triangle^{8}$ ), fraction III methostenol, fraction IV lanosterol and fraction $\mathrm{V}$ diunsaturated dimethyl sterol $\left(4,4\right.$ dimethyl $\left.\triangle^{824}\right)$. The recovery of free methyl sterol added to serum was $93 \pm 2 \%$. Gas liquid chromatography on a capillary column ${ }^{14}$ was used for the quantification of cholesterol precursors when the effect of a gluten free diet on cholesterol synthesis was studied.

The faecal neutral steroids and bile acids were analysed using thin layer chromatography and gas liquid chromatography. ${ }^{15} 16$ As the recovery of beta-sitosterol appeared to be practically complete in every case, the faecal steroid data are expressed in relation to chromic oxide. The stool fat determination was performed according to van der Kamer. $^{17}$

Table 1 Clinical and laboratory data in control subjects and in patients with coeliac disease before and during the gluten free diet (GFD). Mean $\pm S E M$

\begin{tabular}{|c|c|c|c|}
\hline \multirow[b]{2}{*}{ Parameter } & \multirow{2}{*}{$\begin{array}{l}\text { Control } \\
(n=6)\end{array}$} & \multicolumn{2}{|c|}{ Patients $(n=12)$} \\
\hline & & Before $G F D$ & During $G F D$ \\
\hline Age, yr & $29 \pm 2$ & $36 \pm 4$ & \\
\hline Sex, F/M & $3 / 3$ & $6 / 6$ & \\
\hline Duration of GFD, & & & \\
\hline $\begin{array}{l}\text { months } \\
\text { Body weight, kg }\end{array}$ & $\overline{62} \pm 5$ & $-58 \pm 3$ & $\begin{array}{c}9 \cdot 2 \pm 2 \cdot 8 \\
65 \pm 28\end{array}$ \\
\hline $\begin{array}{l}\text { Faecal fat, }{ }^{*} \text { g/day } \\
\text { Faecal steroids, mg/day }\end{array}$ & - & $22 \cdot 4 \pm 4 \cdot 5$ & $6 \cdot 6 \pm 1 \cdot 3 \ddagger$ \\
\hline Bile acids & $238 \pm 50$ & $312 \pm 60$ & $300 \pm 33$ \\
\hline Neutral steroids & $638 \pm 106$ & $1361 \pm 115 \dagger$ & $729 \pm 48 \ddagger$ \\
\hline Total steroids & $876 \pm 118$ & $1673 \pm 142 \dagger$ & $1029 \pm 55 \ddagger$ \\
\hline $\begin{array}{l}\text { Cholesterol synthesis, } \\
\text { mg/day }\end{array}$ & $776 \pm 118$ & $1574 \pm 141 \dagger$ & $927 \pm 56 \ddagger$ \\
\hline
\end{tabular}

${ }^{*}$ Normal $<7.0 \mathrm{~g} /$ day, $\nmid \mathrm{p}<0.001$ from the control values, $\neq \mathrm{p}<0.01$ and $\$ p<0.001$ from the pretreatment values 


\section{CALCULATIONS}

The cholesterol synthesis was obtained by subtracting the dietary cholesterol from the sum of faecal neutral steroids and faecal bile acids.

To eliminate the effect of the serum cholesterol level on the cholesterol precursor concentrations, the precursor levels are expressed per $100 \mathrm{mg}$ of free

Table 2 Free and esterified methyl sterols in serum of control subjects $(n=6)$ and patients $(n=6)$ with coeliac disease. Mean $\pm S E M$

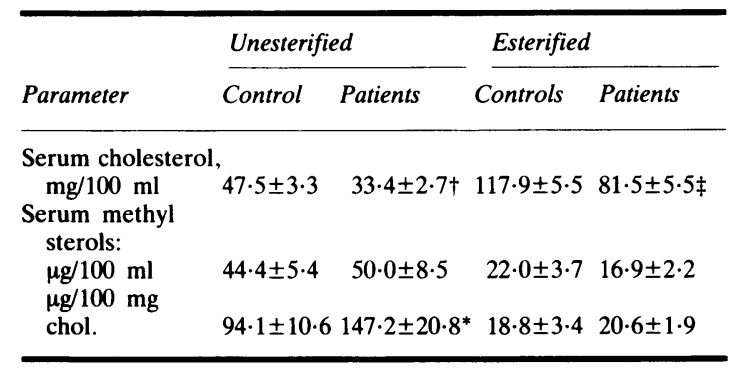

${ }^{*} \mathrm{p}<0.05,+\mathrm{p}<0.01, \neq \mathrm{p}<0.001$ from control values or esterified cholesterol in serum. ${ }^{8}$ The statistical analysis was made with the Student's $t$-test and the paired $t$-test where appropriate. Means \pm SEM are given in the text.

\section{Results}

The clinical and faecal data for the 12 patients with coeliac disease, matched for age, sex and body weight with six controls, are presented in Table 1. The mean faecal bile acid excretion was normal, but the levels of faecal neutral steroids and faecal fat were clearly increased, indicating moderately severe coeliac disease. Cholesterol synthesis was twice as high in the patients as in the controls. With the gluten free diet all the data were clearly improved, even though cholesterol synthesis was still slightly increased.

SERUM METHYL STEROLS IN UNTREATED PATIENTS Both the serum free and esterified methyl sterol levels were determined for six controls and for six patients with untreated coeliac disease (Table 2). In

Table 3 Effect of the gluten free diet (GFD) upon serum squalene, free and esterified methyl sterols, desmosterol, lathosterol and cholesterol levels in 12 patients. Mean $\pm S E M$

\begin{tabular}{|c|c|c|c|}
\hline $\begin{array}{l}\text { Parameter } \\
\mu \mathrm{g} / 100 \mathrm{mg} \text { cholesterol }\end{array}$ & $\begin{array}{l}\text { Before } \\
\text { GFD }\end{array}$ & $\begin{array}{l}\text { During } \\
\text { GFD }\end{array}$ & Change \\
\hline Squalene & $17 \cdot 2 \pm 8 \cdot 0$ & $14 \cdot 7 \pm 3 \cdot 5$ & $-2 \cdot 5 \pm 7 \cdot 0$ \\
\hline \multicolumn{4}{|l|}{ Methyl sterols: (a) } \\
\hline \multicolumn{4}{|l|}{ Unesterified } \\
\hline I & $22 \cdot 1 \pm 4 \cdot 2$ & $15 \cdot 1 \pm 2 \cdot 4$ & $-7 \cdot 0 \pm 8 \cdot 0^{*}$ \\
\hline II & $19 \cdot 6 \pm 4 \cdot 0$ & $12 \cdot 5 \pm 2 \cdot 2$ & $-7 \cdot 1 \pm 2 \cdot 7^{*}$ \\
\hline III & $28 \cdot 7 \pm 5 \cdot 4$ & $18 \cdot 3 \pm 3 \cdot 2$ & $-10 \cdot 4 \pm 3 \cdot 4^{*}$ \\
\hline IV & $38 \cdot 5 \pm 7 \cdot 5$ & $26 \cdot 8 \pm 4 \cdot 0$ & $-11 \cdot 7 \pm 4 \cdot 5^{*}$ \\
\hline $\mathrm{V}$ & $25 \cdot 4 \pm 2 \cdot 5$ & $18 \cdot 9 \pm 2 \cdot 0$ & $-6 \cdot 5 \pm 2 \cdot 0 \dagger$ \\
\hline Sum & $134 \cdot 3 \pm 18 \cdot 6$ & $91 \cdot 0 \pm 10 \cdot 0$ & $-42 \cdot 7 \pm 13 \cdot 1 \dagger$ \\
\hline \multicolumn{4}{|l|}{ Esterified: (b) } \\
\hline I & $5 \cdot 6 \pm 0 \cdot 6$ & $5 \cdot 3 \pm 0 \cdot 5$ & $-0 \cdot 3 \pm 0 \cdot 2$ \\
\hline II & $1 \cdot 2 \pm 0 \cdot 1$ & $0 \cdot 8 \pm 0 \cdot 1$ & $-0 \cdot 4 \pm 0 \cdot 1^{*}$ \\
\hline III & $11 \cdot 5 \pm 1 \cdot 2$ & $8 \cdot 8 \pm 0 \cdot 5$ & $-2 \cdot 7 \pm 0 \cdot 9^{*}$ \\
\hline IV & $1 \cdot 4 \pm 0 \cdot 1$ & $1 \cdot 2 \pm 0 \cdot 1$ & $-0 \cdot 2 \pm 0 \cdot 1$ \\
\hline $\mathrm{V}$ & $0 \cdot 9 \pm 0 \cdot 1$ & $0.8 \pm 0.04$ & $-0 \cdot 2 \pm 0 \cdot 1$ \\
\hline Sum & $20 \cdot 6 \pm 1 \cdot 9$ & $16 \cdot 9 \pm 1 \cdot 0$ & $-3 \cdot 7 \pm 1 \cdot 0^{*}$ \\
\hline Sum, $E^{(c)} \%$ & $26 \cdot 3 \pm 2 \cdot 3$ & $32 \cdot 7 \pm 10 \cdot 2$ & $+6 \cdot 4 \pm 4 \cdot 1$ \\
\hline \multicolumn{4}{|l|}{ Desmosterol: (h) } \\
\hline Total & $44 \cdot 3 \pm 4 \cdot 1$ & $39 \cdot 2 \pm 3 \cdot 2$ & $-5 \cdot 1 \pm 4 \cdot 8$ \\
\hline $\mathrm{E}^{\text {(c) }} \%$ & $75 \cdot 8 \pm 1 \cdot 1$ & $78 \cdot 8 \pm 0 \cdot 8$ & $+3.0 \pm 1.6$ \\
\hline \multicolumn{4}{|l|}{ Lathosterol: (b) } \\
\hline Total & $202 \cdot 6 \pm 32 \cdot 0$ & $128 \cdot 8 \pm 14 \cdot 8$ & $-73 \cdot 8 \pm 23 \cdot 4^{*}$ \\
\hline $\mathrm{E}^{(\mathrm{c})} \%$ & $41 \cdot 0 \pm 2 \cdot 0$ & $45 \cdot 5 \pm 2 \cdot 2$ & $+4 \cdot 5 \pm 3 \cdot 6$ \\
\hline \multicolumn{4}{|l|}{ Cholesterol, $\mathrm{mg} / 100 \mathrm{ml}$} \\
\hline Total & $115 \cdot 1 \pm 7 \cdot 9$ & $152 \pm 15 \cdot 0$ & $+37 \cdot 1 \pm 11 \cdot 6^{*}$ \\
\hline $\mathrm{E}^{(\mathrm{c})} \%$ & $70 \cdot 9 \pm 0 \cdot 9$ & $71 \cdot 6 \pm 0 \cdot 7$ & $+0 \cdot 8 \pm 0 \cdot 9$ \\
\hline
\end{tabular}

${ }^{*} \mathrm{p}<0 \cdot 05, \dagger \mathrm{p}<0 \cdot 01, \neq \mathrm{p}<0 \cdot 001$

(a) Composition of the various subfractions: $I=\Delta^{8}-$ methostenol and some dihydrolanosterol; II $=\Delta^{8}-(4 \alpha, 4 \beta)$ dimethyl sterol; III =methostenol; IV =lanosterol; $V=\Delta^{824}-(4 \alpha, 4 \beta)$ dimethylsterol

(b) $n=6$

(c) Percentage of esterification

The respective faecal steroid data are presented in Table 1. 
terms of $\mu \mathrm{g} / \mathrm{mg}$ of cholesterol the serum total free methyl sterol level was significantly higher for the patients than for the controls, whereas the total esterified methyl sterol content was not significantly different.

The percentage of esterified cholesterol was similar for the controls $(71 \pm 1 \%)$ and the patients $(72 \pm 1 \%)$, whereas the esterification of serum total methyl sterols was diminished by $20 \%(33 \pm 3 \%$ in controls $v s 26 \pm 2 \%$ in patients).

\section{EFFECT OF GLUTEN FREE DIET}

Because the serum methyl sterol contents were significantly high in the untreated coeliac patients, the effect of gluten free diet on serum cholesterol and its precursors was evaluated in 12 patients. In this series the serum squalene, lathosterol and desmosterol levels were also measured. While the gluten free diet significantly raised the serum free and esterified cholesterol levels in the patients (Table 3), the serum levels of cholesterol precursors were lowered. Of the various precursors only squalene was not significantly decreased, whereas the serum total free methyl sterol level was reduced by one third $(p<0 \cdot 01)$. A decrease of similar magnitude was found in all the serum methyl sterol subfractions I-V. The esterified methyl sterol levels were also significantly decreased by the gluten free diet, but the reduction was only $18 \%$, and was statistically significant for fractions II (monounsaturated dimethyl sterol) and III (methostenol).

The serum total desmosterol level was only insignificantly reduced by the gluten free diet while that of lathosterol showed a marked decrease during the treatment (Table 3).

The gluten free diet had no effect on the degree of esterification of serum cholesterol, but tended to increase that of cholesterol precursors, especially of methyl sterols, and less so those of desmosterol and lathosterol (Table 3).

\section{CORRELATIONS}

An examination of the relationships between various precursors revealed a positive correlation between the free and esterified forms of serum methyl sterols $(r=0.54, p<0.05)$, particularly with methostenol $(\mathrm{r}=0.87 ; \quad \mathrm{p}<0.001)$, desmosterol $(\mathrm{r}=0.77 ; \quad \mathrm{p}<0.01)$ and lathosterol $(\mathrm{r}=0.90$; $\mathrm{p}<0.001)$. In contrast to the esterified forms, the serum free methyl sterol and lathosterol, but not desmosterol, levels were positively correlated with the level of cholesterol synthesis (Fig. 2).

\section{CHOLESTYRAMINE TREATMENT}

In the controls cholestyramine reduced the serum free cholesterol and increased faecal elimination of cholesterol by a factor of 3.3 as bile acids (Table 4 ) and serum total free methyl sterols by a factor of $4 \cdot 6$. The diunsaturated dimethyl sterol level exhibited the highest absolute and relative increase, while the level of methostenol was not significantly increased.

In the coeliac patients the faecal bile acid level and total steroid excretions were also increased by cholestyramine, but not as markedly as in the controls (Table 4). The decrease in the serum free cholesterol level $(-10 \%)$ was insignificant and less than in the controls $(-30 \%)$. The increase in serum free methyl sterols was also lower in the patients than in the controls mainly as a result of an only two-fold rise in fraction $\mathrm{V}$ as compared with

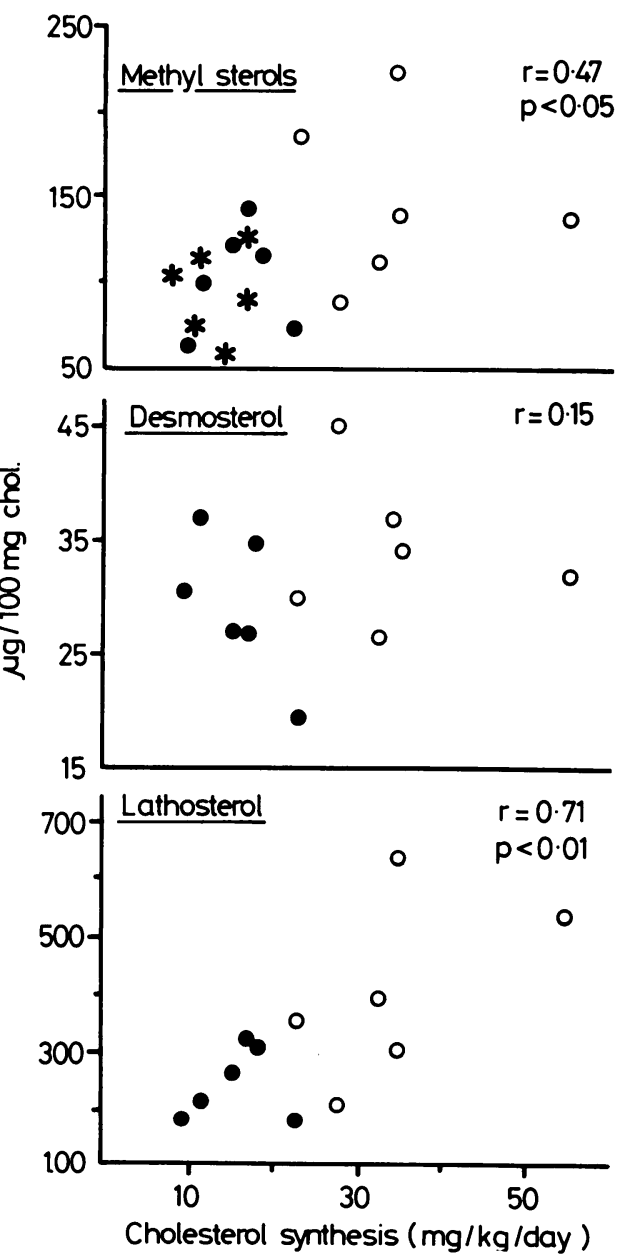

Fig. 2. Correlation of the level of cholesterol synthesis with serum free methyl sterol, desmosterol and lathosterol levels in the controls $(x)$ and coeliac patients before $(O)$ and during (O) a gluten-free diet. 
Table 4 Comparison of the effect of cholestyramine (32 g/day) on serum total and free cholesterol, serum free methyl sterols, faecal fat and faecal steroids in six control subjects and in five untreated coeliac patients. Mean $\pm S E M$

\begin{tabular}{|c|c|c|c|c|}
\hline \multirow[b]{2}{*}{ Parameter } & \multicolumn{2}{|l|}{ Controls } & \multicolumn{2}{|l|}{ Patients } \\
\hline & Off & On & Off & On \\
\hline \multicolumn{5}{|c|}{ Serum cholesterol, $\mathrm{mg} / 100 \mathrm{ml}$ : } \\
\hline Total & $165 \cdot 4 \pm 8 \cdot 3$ & $118 \cdot 3 \pm 7 \cdot 1 \ddagger$ & $172 \cdot 6 \pm 15 \cdot 1$ & $149 \cdot 4 \pm 10 \cdot 7$ \\
\hline Free & $47 \cdot 5 \pm 3 \cdot 3$ & $32 \cdot 1 \pm 2 \cdot 2 \dagger$ & $36 \cdot 7 \pm 3 \cdot 6$ & $33 \cdot 1 \pm 4 \cdot 9^{(a)}$ \\
\hline \multicolumn{5}{|c|}{ Serum methyl sterols, ${ }^{(b)} \mu \mathrm{g} / 100 \mathrm{mg}$ chol: } \\
\hline I & $17 \cdot 4 \pm 3 \cdot 2$ & $80 \cdot 9 \pm 14 \cdot 9^{*}$ & $27 \cdot 4 \pm 9 \cdot 7$ & $87 \cdot 1 \pm 32 \cdot 3$ \\
\hline II & $17 \cdot 2 \pm 3 \cdot 8$ & $70 \cdot 6 \pm 16 \cdot 8^{*}$ & $20 \cdot 9 \pm 7 \cdot 0$ & $59 \cdot 4 \pm 24 \cdot 0$ \\
\hline III & $6 \cdot 7 \pm 1 \cdot 3$ & $18 \cdot 1 \pm 4 \cdot 3$ & $17 \cdot 8 \pm 4 \cdot 7$ & $26 \cdot 4 \pm 9 \cdot 0$ \\
\hline IV & $38 \cdot 1 \pm 4 \cdot 1$ & $134 \cdot 4 \pm 12 \cdot 2 \dagger$ & $54 \cdot 3 \pm 15 \cdot 8$ & $149 \cdot 0 \pm 56 \cdot 0$ \\
\hline $\mathrm{V}$ & $14 \cdot 8 \pm 4 \cdot 3$ & $130 \cdot 6 \pm 31 \cdot 9^{*}$ & $24 \cdot 3 \pm 5 \cdot 2$ & $55 \cdot 4 \pm 14 \cdot 2^{*(a)}$ \\
\hline Sum & $94 \cdot 1 \pm 10 \cdot 6$ & $434 \cdot 6 \pm 72 \cdot 6 \dagger$ & $144 \cdot 7 \pm 39 \cdot 1$ & $377 \cdot 4 \pm 114 \cdot 1$ \\
\hline Fecal fat, g/day & - & - & $12 \cdot 9 \pm 4 \cdot 4$ & $24 \cdot 4 \pm 8 \cdot 4$ \\
\hline \multicolumn{5}{|c|}{ Fecal steroids, $\mathrm{mg} /$ day: ${ }^{(\mathrm{c})}$} \\
\hline Bile acids & - & $2151 \pm 231 \ddagger$ & $238 \pm 47$ & $1885 \pm 467^{*}$ \\
\hline Neutral steroids & - & $730 \pm 100$ & $1231 \pm 220$ & $1072 \pm 178$ \\
\hline Total steroids & - & $2881 \pm 234 \ddagger$ & $1470 \pm 220$ & $2958 \pm 400^{*}$ \\
\hline
\end{tabular}

${ }^{*} p<0 \cdot 05, \neq p<0 \cdot 01, \neq p<0.001$ from the pretreatment values

(a) $p<0.05$ from the respective change in the controls

(b) Composition of the subfractions is given in the footnote of Table 3

(c) The initial data of the controls are presented in Table 1 .

nine-fold increase in the controls. Accordingly, the proportion of methyl sterols in fraction $\mathrm{V}$ was increased in the controls $(p<0 \cdot 01)$, while it tended to be decreased in the patients. In the whole series the cholestyramine-induced changes in the faecal total steroid excretion were positively correlated

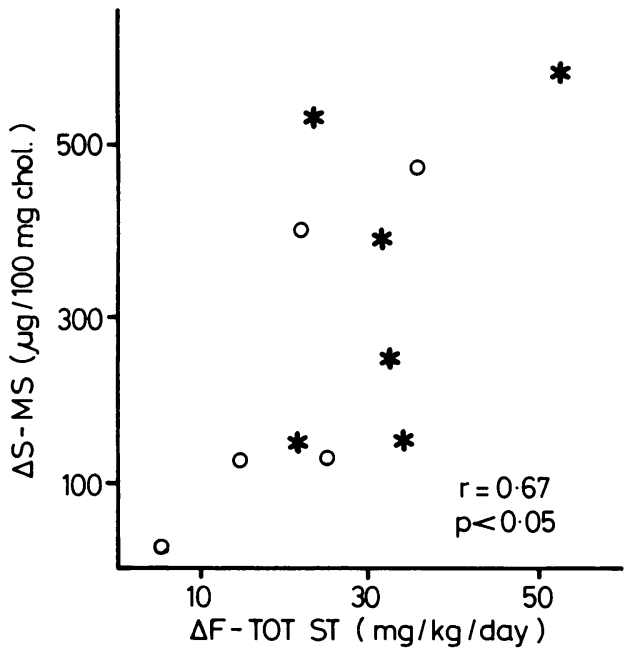

Fig. 3. Correlation of cholestyramine induced changes in serum free methyl sterols $(\triangle S-M S)$ with that in faecal total sterols $(\triangle F-T O T S T)$ in controls $\left(^{*}\right)$ and untreated coeliac patients $(\bigcirc)$. with the corresponding changes in serum total free methyl sterols (Fig. 3) and in the subfraction $\mathrm{V}$ $(r=0.60 ; p<0.05)$.

The gluten free diet and cholestyramine studies revealed that the rise in free methyl sterols in terms of $\mu \mathrm{g} / \mathrm{mg}$ of increase in cholesterol synthesis or

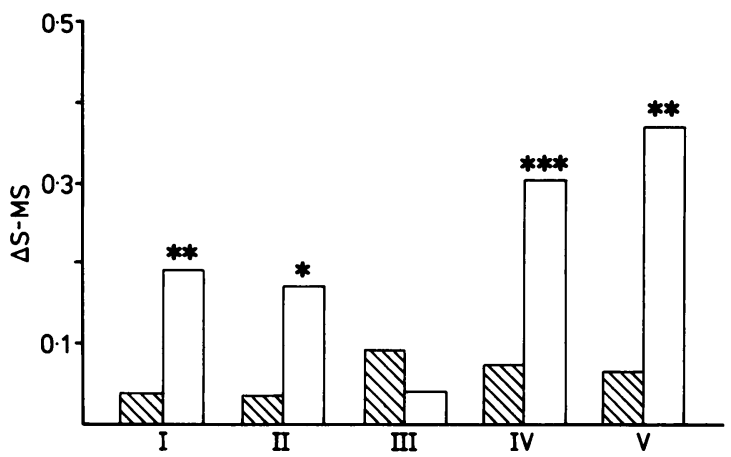

Fig. 4. Changes in levels of serum free methyl sterols $(\triangle S$ $M S)$ in relation to changes in levels of faecal steroids $(\triangle F-T O T S T)$ caused by cholesterol malabsorption $(\mathbb{\$})$ or by bile acid malabsorption ( $\square$ ). The $\triangle S$-MS values are shown, in terms of $\mu \mathrm{g} 10^{-2} \mathrm{mg} \mathrm{S}$-chol./mg F-TOT ST, as changes caused by the gluten-free diet in the patients in Table 3 and by cholestyramine in the controls in Table 4. The composition of the methyl sterol subfractions $(I-V)$ is given in the footnote to Table $3 .{ }^{*} p<0 \cdot 05,{ }^{* *} p<0 \cdot 01,{ }^{* * *} p<0 \cdot 001$. 
elimination, was three times higher with bile acid malabsorption than with cholesterol malabsorption (Fig. 4). Calculations from the data for the subjects in Tables 3 and 4 revealed that a $1 \mathrm{mmol} / \mathrm{l}$ decrease in serum cholesterol required an increase of $27 \pm 7$ $\mu \mathrm{mol} / \mathrm{day} / \mathrm{kg}$ of body weight in the faecal total steroid excretion by cholesterol malabsorption in coeliac patients, and markedly more - that is, $81 \pm 18 \mu \mathrm{mol} / \mathrm{day} / \mathrm{kg}$ of body weight $(\mathrm{p}<0.02)$ in the controls by cholestyramine-induced bile acid malabsorption.

\section{Discussion}

The present results revealed that the markedly higher level of cholesterol synthesis in coeliac disease is associated with a proportionate increase in serum free and esterified lathosterol, and free methyl sterols. This is less true for esterified methyl sterols and not true at all for squalene and desmosterol. The reason for the difference in esterification is that sterols with 27 carbons are esterified by lecithin:cholesterol acyl transferase (LCAT), ${ }^{18}{ }^{19}$ while methyl sterols are not. ${ }^{20}$ The latter ones, especially $4 \alpha$-methyl sterols, are esterified by acylcoenzyme A:cholesterol acyltransferase. ${ }^{11} 22$ Thus, serum methyl sterol esters are derived from tissues and include predominantly methostenols. Accordingly an increase in free lathosterol results in its proportionate esterification by lecithin:cholesterol acyltransferase while an increase in free methyl sterols is not followed by their esterification in serum.

Despite a greatly enhanced intestinal synthesis of cholesterol, ${ }^{4} 5$ both the concentrations and the percentage distribution of methyl sterols are normal in the jejunal mucosa of coeliac patients. ${ }^{5}$ The findings that the serum methyl sterol pattern differs markedly from that in the mucosa ${ }^{5}$ that the chylomicron particles of intestinal origin contain little cholesterol precursors, ${ }^{14}$ and that the cholesterol precursor level in serum is positively correlated with that in bile both at high and low synthesis rates ${ }^{23}$ suggest that changes in cholesterol precursors in serum during fasting mainly reflect changes in hepatic cholesterol synthesis. A markedly increased serum methyl sterol level occurs with a bile acid malabsorption-induced increase in cholesterol synthesis, ${ }^{723}$ while the inhibition of cholesterol synthesis by fasting or chenotreatment $^{24} 25$ is associated with lowered methyl sterol levels in serum. ${ }^{8326}$ Thus, the increase in serum lathosterol and free methyl sterols in coeliac patients, and during cholestyramine treatment proportionately to the increase in the faecal steroid level, was most likely mainly caused by an increase in hepatic cholesterolgenesis.
The present results on the high cholesterol precursor levels in coeliac disease are consistent with the hypothesis that the influx of cholesterol from the gut to the liver does not sufficiently compensate for the increased biliary and faecal cholesterol elimination recorded in these patients, ${ }^{1-3}$ but leads to hepatic cholesterol depletion and to increased hepatic cholesterol synthesis. Cholesterol depletion would reduce the acyl-coenzyme A: cholesterol acyltransferase. ${ }^{27}$ Because of the high levels of cholesterol synthesis, however, the free methyl sterol concentration in hepatocyte would be increased allowing effective esterification and a slightly increased release of methyl sterol esters into the circulation in newly formed very low density lipoprotein.

Acute changes in cholesterol synthesis are also senstively reflected in serum squalene levels. ${ }^{14}$ Short term bile acid malabsorption most effectively increases the levels of free lanosterol, its demethylation product, $\Delta^{824}$-dimethylsterol (Fig. 1) and lathosterol. ${ }^{723}$ However, during long-term followup some adaptation occurs. Thus, rates of squalene cyclisation, $14 \alpha$-demethylation and saturation of side chain double bond appear to be increased in patients with long-term bile acid malabsorption, $4 \alpha 4 \beta$-demethylation, and the conversion of $\triangle^{8}$ to $\Delta^{7}$ and $\Delta^{7}$ to $\Delta^{57}$ remaining most rate-limiting steps. ${ }^{8}{ }^{23} 28$ The gluten free diet study revealed a similar adaptation in coeliac disease.

Neomycin induced cholesterol malabsorption activates postsqualene steps to the extent that the levels of serum methyl sterol are virtually unchanged. ${ }^{29}$ The small rise in serum free methyl sterols in relation to the increase in cholesterol synthesis in cholesterol malabsorption of coeliac disease may also be because of activation of postsqualene steps. In addition, under basal conditions the level of enzyme activity of postmevalonate steps is higher than that for premevalonate steps. ${ }^{30}$ Thus, the flow of acetate to cholesterol may increase to some extent before the postmevalonate enzymes become rate limiting, indicating that a small increase in the rate of cholesterol synthesis, caused either by cholesterol or bile malabsorption, may not result in any marked accumulation of sterol intermediates, including methyl sterols.

In cholesterol malabsorption caused by neomycin the ratio of the decrease in serum cholesterol to the increase in cholesterol elimination (or synthesis) is markedly higher than with bile acid malabsorption. ${ }^{31}$ Similar results were obtained in the present study, indicating that cholesterol malabsorption and bile acid malabsorption reduce serum cholesterol dissimilarly. In fact, kinetic studies of serum lipoproteins also suggest that the mechanism 
for lowering the level of low density lipoprotein is different in the two conditions. ${ }^{32}{ }^{33}$ In brief these findings suggest that the lowering of the serum cholesterol level with cholesterol malabsorption in coeliac disease is mainly attributable to a high biliary output of newly synthesised and/or absorbed cholesterol as compared with that released within very low density lipoprotein into serum, whereas in bile acid malabsorption a proportionately larger amount of newly synthesised and/or absorbed cholesterol is released into serum through increased very low density lipoprotein production and less is secreted directly into the bile. ${ }^{24-37}$

\section{References}

1 Vuoristo M, Tarpila S, Miettinen TA. Serum lipids and fecal steroids in patients with celiac disease: effects of gluten-free diet and cholestyramine. Gastroenterology 1980; 78: 1518-25.

2 Vuoristo M, Miettinen TA. Increased biliary secretion in celiac disease. Gastroenterology 1984; 88: 134-42.

3 Vuoristo M, Miettinen TA. Cholesterol absorption, elimination and synthesis in coeliac disease. Eur J Clin Invest 1982; 12: 285-91.

4 Dietschy JM, Gamel WC. Cholesterol synthesis in the intestine of man: regional differences and control mechanisms. J Clin Invest 1971; 50: 872-80.

5 Vuoristo M, Miettinen TA. Enhanced synthesis of cholesterol and its precursors in jejunal mucosa in coeliac disease. Gut 1986; 27: 399-404.

6 Miettinen TA. Serum squalene and methyl sterols as indicators of cholesterol synthesis in vivo. Life Sci 1969; 8: 713-21.

7 Miettinen TA. Detection of changes in human cholesterol metabolism. Ann Clin Res 1970; 2: 300-20.

8 Miettinen TA. Serum methyl sterols and their distribution between major lipoprotein fractions in different clinical conditions. Ann Clin Res 1971; 3: 264-71.

9 Nestel PJ, Kudchodhar B. Plasma squalene as an index of cholesterol synthesis. Clin Sci Mol Med 1975; 49: 621-4.

10 Liu GCK, Ahrens EH Jr, Schreibman PH, Crouse JR. Measurement of squalene in human tissue and plasma: validation and application. J Lipid Res 1976; 17: 38-45.

11 Grundy SM, Ahrens EJ Jr, Salen G. Dietary $\beta$ sitosterol as an internal standard to correct for cholesterol losses in sterol balance studies. J Lipid Res 1968; 9: 347-87.

12 Davignon J, Simmonds WJ, Ahrens EH Jr. Usefullness of chromic oxide as an internal standard for balance studies in formula-fed patients and assessment of colonic function. J Clin Res 1968; 47: 127-38.

13 Miettinen TA. Methods for evaluation of hypolipidemic drugs in man: mechanisms of their action. In: Paoletti R, Glueck CJ, eds. Lipid pharmacology. London: Academic Press 1976; 2: 83-125.

14 Miettinen TA. Diurnal variation of cholesterol precursor squalene and methyl sterols in human plasma lipoproteins. J Lipid Res 1982; 23: 466-73.
15 Miettinen TA, Ahrens EH Jr, Grundy SM. Quantitative isolation and gas-liquid chromatographic analysis of total dietary and fecal neutral steroids. J Lipid Res 1965; 6: 411-24.

16 Grundy SM, Ahrens EH Jr, Miettinen TA. Quantitative isolation and gas-liquid chromatographic analysis of total fecal bile acids. J Lipid Res 1965; 6: 397-410.

17 van der Kamer JH, ten Bokkel Huinink H, Weyers HA. Rapid method for the determination of fat in feces. J Biol Chem 1949; 177: 347-55.

18 Glomset JA, Parker F, Tjaden M, Williams RH. The esterification in vitro of free cholesterol in human and rat plasma. Biochem Biophys Acta 1962; 58: 398-406.

19 Nordby G, Norum K. Substrate specifity of lecithin: cholesterol acyl-transferase, esterification of desmosterol, $\beta$-sitosterol and cholecalciferol in human plasma. Scand J Clin Lab Invest 1975; 35: 677-82.

20 Tilvis RS, Miettinen TA. A lack of esterification of lanosterol and other methyl sterols in human serum in vitro. Scand J Clin Lab Invest 1980; 40: 671-74.

21 Brady DR, Gaylor JL. Enzymatic formation of esters of methyl sterol precursors of cholesterol. J Lipid Res 1971; 12: 270-6.

22 Tavani DM, Nes WR, Billheimer JT. The sterol substrate specifity of acyl CoA:cholesterol acyltransferase from rat liver. $J$ Lipid Res 1982; 23: 774-81.

23 Miettinen TA. Effects of bile acid feeding and depletion on plasma and biliary squalene, methyl sterols and lathosterol. In: Paumgartner G, Stiehl A, Gerok W, eds. Bile acids and lipids. Lancaster: MTP Press Limited:, 1981: 255-62.

24 Dietschy JM, Wilson JD. Regulation of cholesterol metabolism. N Engl J Med 1970; 282: 1128-38.

25 Coyne MI, Bonorris GG, Goldstein JL, Schoenfield LJ. Effect of chenodeoxycholic acid and phenobarbital on the rate-limiting enzymes of hepatic cholesterol and bile acid synthesis in patients with gallstones. $J$ Lab Clin Med 1976; 87: 281-91.

26 Miettinen TA. Lanosterol and other methyl sterols in serum of fed and fasted human subjects. Ann Med Exp Fenn 1968; 46: 171-6.

27 Erikson SK, Shrewsbury MA, Brooks C, Mayer DJ. Rat liver acyl-coenzyme A: cholesterol acyltransferase: its regulation in vivo and some of its properties in vitro. J Lipid Res 1980; 21: 930-41.

28 Miettinen TA. Cholesterol precursors and their diurnal rhythm in lipoproteins of patients with jejuno-ileal bypass and ileal dysfunction. Metabolism 1985; 34: 425-30.

29 Miettinen TA. Effects of neomycin alone and in combination with cholestyramine on serum methyl sterols and conversion of acetate and mevalonate to cholesterol. Scand J Clin Lab Invest 1982; 42: 189-96.

30 Gould RG, Swyrud EA. Sites of control of hepatic cholesterol biosynthesis. J Lipid Res 1966; 7: 698-707.

31 Miettinen TA. Effects of neomycine alone and in combination with cholestyramine on serum cholesterol and fecal steroids in hypercholesterolemic subjects. $J$ Clin Invest 1979; 64: 1485-93.

32 Kesäniemi YA, Vuoristo M, Miettinen TA.Metabolism of very low density and low density lipoproteins in patients with coeliac disease. In: Carlson LA, Olsson 
AG, eds. Proceedings of the 41st European Atherosclerosis Group Meeting, Stockholm. New York: Raven Press, 1983: 49-53.

33 Kesäniemi YA, Miettinen TA. Receptor vs nonreceptor mediated catabolism in patients with coealic disease and intestinal resections. In: Schletter G, Augustin J, eds. New aspects in lipoprotein metabolism. Heidelberg: Thieme. (In press).

34 Kesäniemi YA, Grundy SM. Turnover of low density lipoproteins during inhibition of cholesterol absorption by neomycin. Arteriosclerosis 1984; 4: 41-8.
35 Angelin B. Cholesterol and bile acid metabolism in normo-and hyperlipoproteinaemia. Acta Med Scand 1977; suppl 610: 1-40.

36 Shepherd J, Packard CJ, Bicker S, Lawrie TDV, Morgan HG. Cholestyramine promotes receptormediated low-density-lipoprotein catabolism. $N$ Engl J Med 1980: 302: 1219-22.

37 Koivisto P. Miettinen TA. Effect of ileal exclusion on kinetics of very low density lipoprotein triglycerides in familial hypercholesterolemia. Clin Clin Acta 1986. (In press). 